\title{
Use of Carbon Dioxide for Transport of Rabbit Meat
}

\author{
Evgeny N. Neverov \\ Department of Heating, Ventilation, and \\ Air Conditioning Systems \\ Kemerovo State University \\ Kemerovo, Russia
}

\author{
Alexey N. Grinyuk \\ Department of Heating, Ventilation, and \\ Air Conditioning Systems \\ Kemerovo State University \\ Kemerovo, Russia
}

\begin{abstract}
In recent years, the production and consumption of rabbit meat have increased since it has a number of advantages compared to other types of meat, and refrigerated rabbit meat, unlike frozen meat, has higher palatability, retains a greater number of micro and macronutrients. At the same time, there is a big disadvantage - the storage time, which is much less for refrigerated rabbit meat. On cooling, during transportation of meat, there is no need for its fast delivery to chilled warehouses, and the transport time is limited only by the admissible shelf life of the chilled product. Transportation of the meat using snowlike carbon dioxide significantly reduces the drying of meat, and the air-gas medium, created during sublimation of snowlike $\mathrm{CO} 2$, prevents deterioration of the product quality to a minimum. When the environment temperature increases by 5 pe ${ }^{0} \mathrm{C}$ during meat transportation, heat inputs through the enclosure structures of the external heatinsulated contour increase, which leads to an increase in the sublimation rate of snowlike carbon dioxide and, respectively, the duration of the product transportation, as well as the intensity of the process of refrigerating carcass rabbit, decrease.
\end{abstract}

Keywords-carnbon dioxide, rabbit meat, transport, food supplym refrigeration

\section{INTRODUCTION}

Transport of meat is one of the most important processes in the food industry chain, which can take from several hours to several days. Being transported the meat is exposed to physico-biological processes, starting from the slaughter, that over time have a negative impact on the quality, freshness and appearance of the product.

When cooled during the transportation, there is no need for fast delivery of meat to refrigerated warehouses, and the transport time is limited only by permissible storage periods of the cooled product.

In our country, the production and consumption of chilled rabbit meat is currently increasing due to a number of advantages as compared to other types of meat. Moreover, unlike frozen meat, chilled rabbit meat, has higher palatability traits, retains a greater number of micro and macronutrients. However, there is a big drawback. It is the storage duration that is much less for chilled rabbit meat $[1,2,4,13]$.

\section{PROBLEM OVERVIEW}

Road, rail and water vehicles are used today to enable the transportation of food products. Insulated refrigerated trucks, as well as special bodies equipped with standard cooling units preserving a predetermined temperature in the cargo compartment, are widely used for the transportation of products by retail and wholesale enterprises. The advantage of this type of transportation is the unlimited delivery time, as the refrigerating unit can operate without time limits, yet the energy losses to drive the compressor of the refrigeration system are sufficient. Since the thermal treatment in the truck box is most often performed by means of air forced convection, there is a significant shrinkage of meat during transportation, which results in the product to lose its market quality.

Specially equipped vehicles with a temporary source of cold (for example, water ice) are also used for transporting some foods when they are cooled. This type of transportation does not imply energy and, consequently, economic costs, since the heat emitted by the product is reduced by a temporary source of cold.

Where the water ice is a source of cold, this method of transportation is also one of the most economical and environmentally friendly. Yet, it has several disadvantages, namely: the ice occupies a significant part of the effective body space, a significant amount of electricity is consumed to produce it in ice generators, and there are difficulties in keeping sanitary requirements in the body space $[6 ; 7 ; 8 ; 11]$.

The use of snow-like carbon dioxide significantly reduces the shrinkage of meat during transportation. Moreover, the snow-like $\mathrm{CO}_{2}$ sublimation by which the air-gas medium is created prevents the product quality from worsening.

When cooling a product with snow-like $\mathrm{CO}_{2}$, there is a possibility to freeze it, since its sublimation temperature is about minus $79^{\circ} \mathrm{C}$. The resulting partial crystal formation does not cause significant changes in the muscle tissue. Lowering the temperature slightly below the cryoscopic point contributes to a significant autolytic slowdown and the extension of "life" 2-3 times compared to chilled foods [5].

With solid carbon dioxide, it becomes possible to transport meat over long distances, since the temperature inside the storage cooler during transportation is generated by the air-gas medium resulted from the sublimation of snow-like carbon dioxide.

Fig. 1 and Fig. 2 show a model of a thermally insulated body for refrigerated processing and transporting rabbit carcasses in carbon dioxide. 


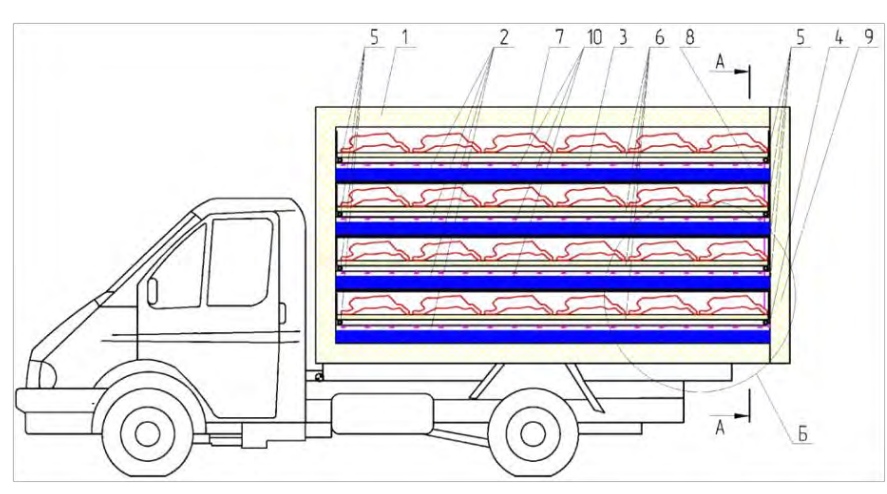

Fig. 1. Vehicle body mockup for $\mathrm{CO}_{2}$ refrigeration of rabbit carcasses
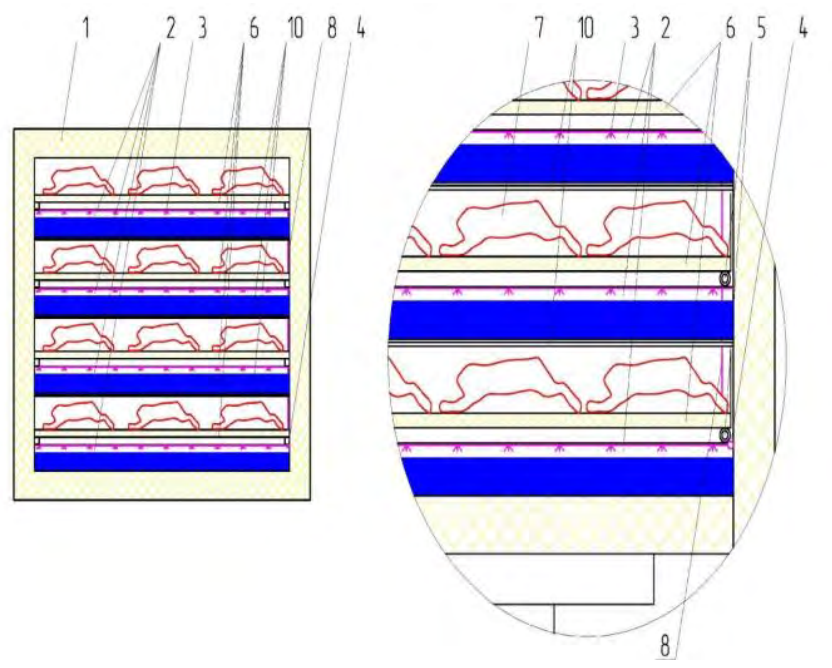

Fig. 2. Section of heat-insulated body for $\mathrm{CO}_{2}$ refrigeration of rabbit carcasses

The body is insulated with a thermally insulated layer (1). The interior lining panel is made from automobile body sheet, and the exterior panel - from aluminum sheet. The thermal insulation is put between the panels. The inner part of the body is divided into compartments (2), into which the snowlike carbon dioxide is supplied through the nozzles (3). $\mathrm{CO} 2$ is supplied through the valve (4). Along the body there are roller guides (5) for moving steel boxes (6) with insulated bottoms into which rabbit carcasses are preloaded (7). The internal cavity of the door (9) is also filled with heat-insulated material with a view to preventing the inflow of heat.

For the supply of snow-like carbon dioxide in each of the cavities of the compartments, rows of nozzles are installed inside the latter along the entire body. $\mathrm{CO} 2$ is distribution to the rows of nozzles in the compartments through the distribution pipe (8).

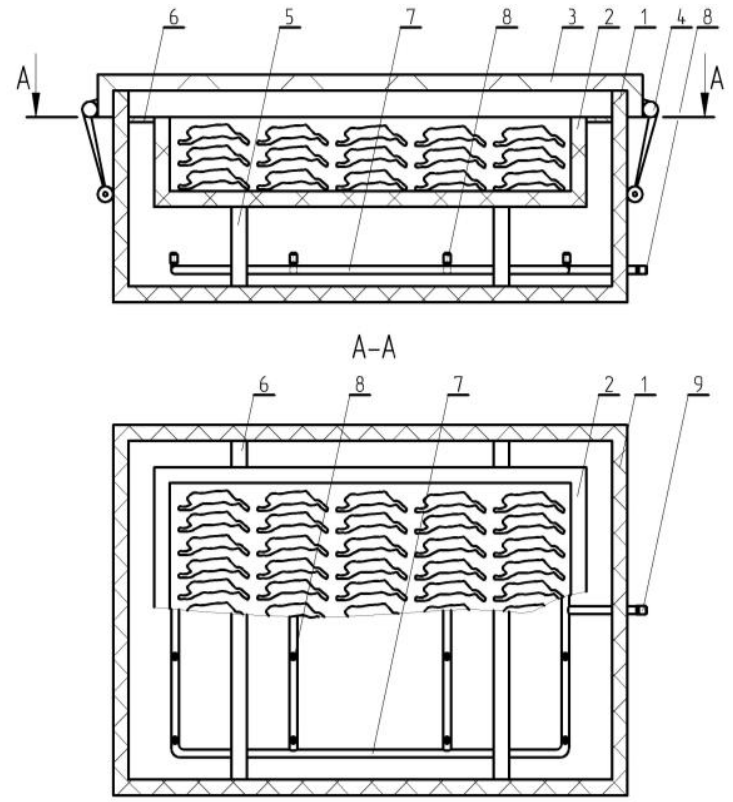

Fig. 3. Container for transport of rabbit meat

Thanks to the bulkheads (10), the insulated body has four separate sections in the event a partial load is required.

To ensure the transport of meat goods in small quantities, the container shown in Fig. 3 is designed.

The container includes an exterior heat insulation (1), an interior heat insulation (2), an exterior insulation cover (3), clamps (4), supports (5), bulkheads (6), distribution pipes (7), throttling nozzles (8), and liquid CO2 feed inlet (9).

The cooled product is placed within the interior insulated loop (2). The interior cavity of the container is isolated from the external environment by closing the external heat insulation (1) with a cover (3).

The source of liquid carbon dioxide is connected to the feed inlet (9). Carbon dioxide is fed into the interior block of the container through distribution pipes (7). CO2 coming through throttling nozzles (8) changes its state from liquid to snow-like. The supports of the internal heat-insulated loop (5) with bulkheads (6) form a free space that is subsequently filled with snow-like carbon dioxide. The bulkheads (6) also do not allow the throttling snow to get into the cavity of the inner heat-insulated loop and, as a result, onto the surface of the transported product.

The template is used to format your paper and style the text. All margins, column widths, line spaces, and text fonts are prescribed; please do not alter them. You may note peculiarities. For example, the head margin in this template measures proportionately more than is customary. This measurement and others are deliberate, using specifications that anticipate your paper as one part of the entire proceedings, and not as an independent document. Please do not revise any of the current designations. 


\section{EXPERIMENTAL INVESTIGATION OF THE EQUIPMENT}

For the implementation of the proposed technology in the industry, the transportation of rabbit meat in the developed containers was studied.

The experiments were aimed at determining the correlation of the changed temperature pattern of a rabbit carcass, both in time, thickness and density of heat fluxes. The paper considers the temperature change inside the container and determination of the shipping time provided that the normalized temperature is maintained.

The carcasses of rabbits weighing $1.3 \mathrm{~kg}$ loaded into containers for transportation were used as the object of study (Fig. 3)

The measurements were carried out in a thigh of a rabbit carcass using four thermocouples and a heat flux density sensor. The thermocouples were installed in the rabbit's thigh: in the inner layer $(15 \mathrm{~mm})$; in the flesh $(7 \mathrm{~mm})$; on the outer surface $(1 \mathrm{~mm})$. The fourth thermocouple controlled the temperature in the heat-insulated block (7).

The density of the heat flux was measured by a heat flux sensor installed in the thigh of the rabbit carcass

The amount of carbon dioxide supplied to the container was $3.5 \mathrm{~kg}$. The ambient air temperature in the first group of experiments was $35^{\circ} \mathrm{C}$.

The thermograph of refrigerating a rabbit carcass with a weight of $1.3 \mathrm{~kg}$ at an ambient air temperature of $35^{\circ} \mathrm{C}$ and the diagram of installing the thermocouples is presented in Fig. 4.

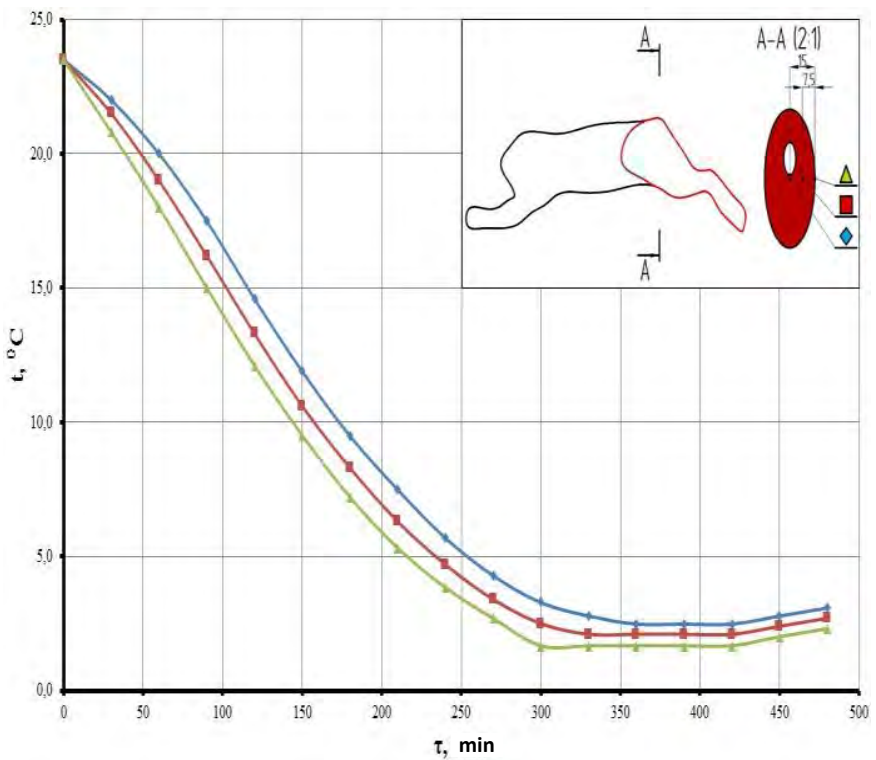

Fig. 4. Thermograph of refrigerating a rabbit carcass with a weight of $1.3 \mathrm{~kg}$ at an ambient air temperature of $35^{\circ}$

The time of complete sublimation of carbon dioxide and transportation, was 7 hours.

The time to reach the normalized temperature of the refrigerated rabbit carcass was about 4.6 hours.
The thermograph (Fig. 4) shows that during the first 5 hours the cooling of all layers of the carcass was intense due to the fact that the temperature difference between the $\mathrm{CO}_{2}$ and rabbit carcass environments was maximum, relative to the temperature difference during the remaining cooling period.

After 5 hours, the temperature in the outer layer of the thigh became constant and remained the same up to 7 hours. This is due to the fact that the amount of carbon dioxide in the container by the beginning of the process sublimated, diverting the heat from the environment through the enclosing structures of the external insulated loop of the container, thus reducing the heat removal from the rabbit carcass.

The temperature in the flesh (thigh muscles) in the middle section had a similar dynamics, but the stage of temperature stabilization started from 5.5 hours and lasted up to 7 hours.

The refrigeration in the thigh muscles near the bones was similar to that in the flesh and on the outer layer of the thigh. The transition time of the intensive cooling to the steady state took 6 hours.

At the end of $\mathrm{CO}_{2}$ sublimation, the temperature in the thigh muscles near the bones was $2.5^{\circ} \mathrm{C}$, while the temperature in the flesh of the thigh in the middle section was within $2.1^{\circ} \mathrm{C}$. The temperature of the outer layer was fixed at $1.7^{\circ} \mathrm{C}$. At this ambient temperature, the normalized temperature in the rabbit carcass was achieved [3].

All loaded carbon dioxide sublimated after 7 hours and the heat inflows coming through the enclosing structures of the external heat-insulated loop contributed to an increase in the temperature of the $\mathrm{CO}_{2}$ environment, as well as an increase in the temperature in all layers of the rabbit's thigh

Fig. 5 shows a graph depicting the change in the heat flux density while cooling a rabbit with a weight of $1.3 \mathrm{~kg}$ with the supply of snow-like $\mathrm{CO}_{2}$ in the inter-block cavity of the container at $t_{\text {a.t. }}=35^{\circ} \mathrm{C}$. In this case, the average integral value of the heat flux density is $\mathrm{q}_{\mathrm{av}}=35 \mathrm{~W} / \mathrm{m}_{2}$, the maximum heat flux density is $\mathrm{q}_{\max }=140 \mathrm{~W} / \mathrm{m}_{2}$.

In the first half an hour of the experiment, the heat flux rapidly increased, reaching a maximum value. 


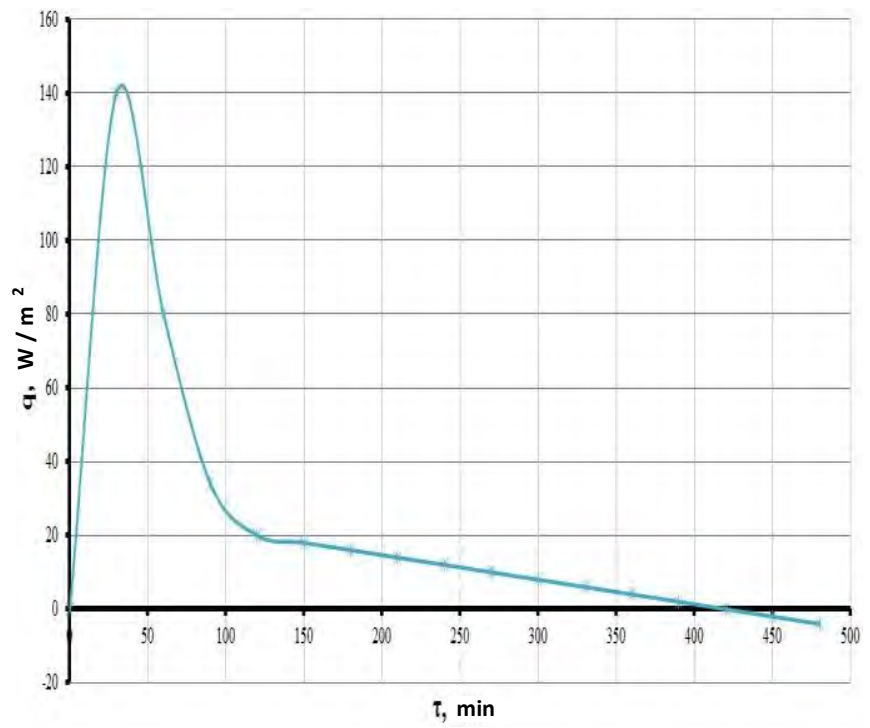

Fig. 5. Change in the heat flux density when refrigerating the rabbit carcass with a weight of $1.3 \mathrm{~kg}$ at ta.t. $=35^{\circ} \mathrm{C}$

Due to the rapid pulldown of temperature of the rabbit carcass that begins after 0.5 hour and continues up to 2 hours, it is observed a sharp decrease in the heat flux density.

After 2 hours, the heat flux density begins to gradually approach zero until the transportation finishes.

After 7 hours of transportation, the heat flux density begins to take negative values, since the sublimation of snow-like carbon dioxide loaded into the cavity between the heatinsulated loops ended.

Figure 6 shows the change in the heat transfer coefficient when refrigerating the carcass of a rabbit with a weight of 1.3 $\mathrm{kg}$.

In the first half an hour of the experiment, peak values of the heat transfer coefficient occur.

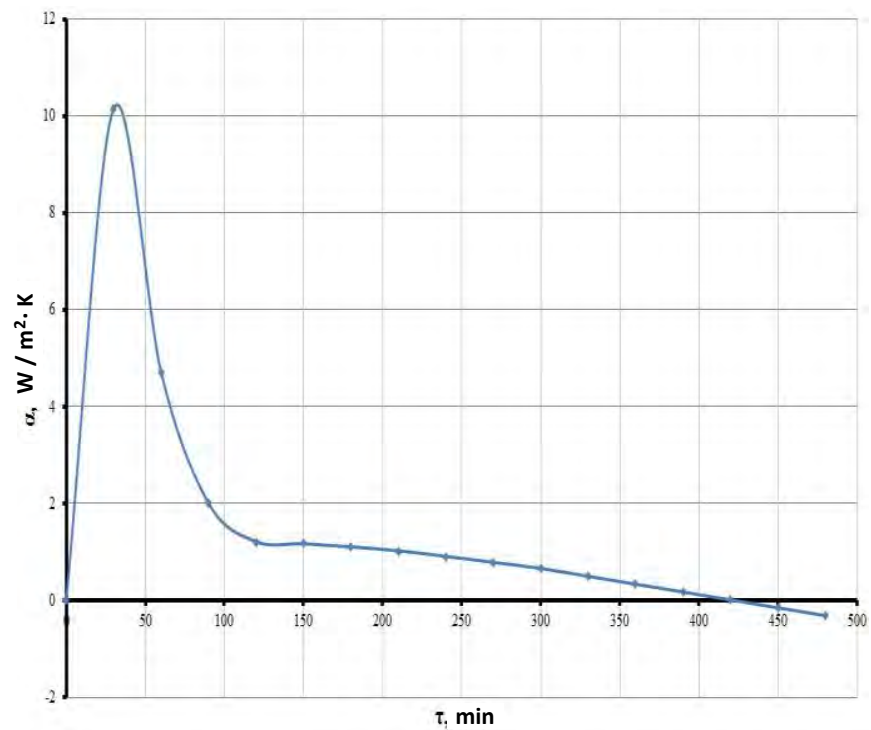

Fig. 6. Change in heat transfer coefficient during refrigeration of the carcass of a rabbit with a weight of $1.3 \mathrm{~kg}$ at ta.t. $=35^{\circ} \mathrm{C}$

Later on in the period from 0.5 to 2 hours, the heat transfer coefficient sharply decrease, since the temperature difference between the $\mathrm{CO} 2$ and rabbit carcass environments begins to decline rapidly. After that, the temperature difference gradually goes down, which leads to a decrease in the heat transfer coefficient.

Analyzing the obtained heat transfer coefficient, it can be concluded that the average integral value of the heat transfer coefficient is $1.4 \mathrm{~W} /\left(\mathrm{m}^{2} \times \mathrm{K}\right)$. The maximum value of the heat transfer coefficient is $10 \mathrm{~W} /\left(\mathrm{m}^{2} \times \mathrm{K}\right)$.

Further studies were carried out while decreasing the ambient air temperature to $10^{\circ} \mathrm{C}$. The dynamics of the cooling process corresponds to the above. The research results are presented in the graph in Fig. 7 that is designed to determine the required amount of snow-like carbon dioxide for refrigerating rabbit carcasses while being transported.

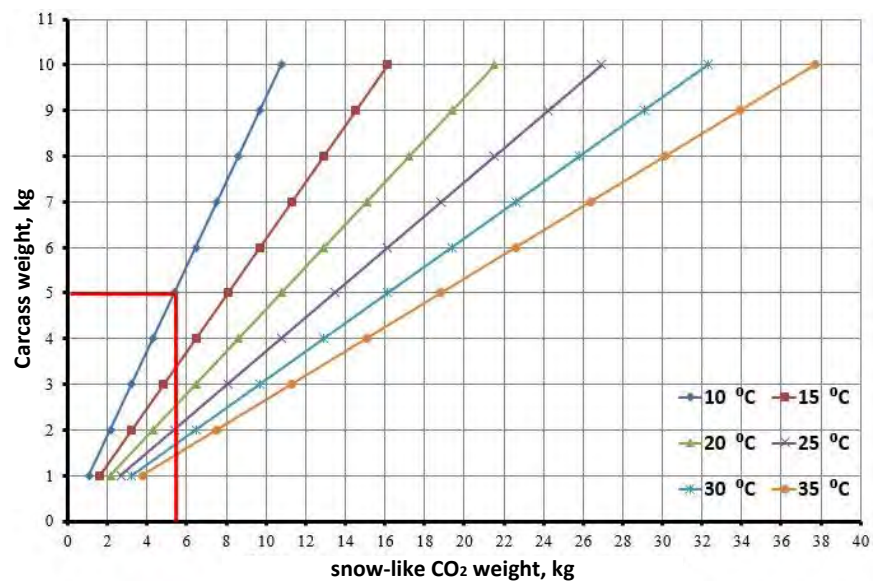

Fig. 7. The required amount of snow-like carbon dioxide fed into the containers for transport of rabbit carcasses 


\section{CONCLUSION}

In this graph, the required weight of snow-like carbon dioxide $(\mathrm{kg})$ is located at the $\mathrm{x}$-axis, while the weight of rabbit carcasses to be transported $(\mathrm{kg})$ is at the y-axis. The isotherms of ambient temperatures are in the working area of the diagram: from $10^{\circ} \mathrm{C}$ to $35^{\circ} \mathrm{C}$. The maximum transportation time of meat is 18.5 hours. The graph should be dealt with in the following way. At the mrabbit-axis=const, the intersection point with the required environmental isotherm is found. From the obtained point, the perpendicular to the $\mathrm{x}$-axis is drawn and the required mass of snow-like carbon dioxide is determined. For more convenient practical work, a program was developed based on the obtained experimental data.

Thus, when the ambient temperature rises by 5 degrees, the heat influx through the enclosing structures of the exterior thermally insulated loop increases. This leads to an increase in the sublimation rate of snow-like carbon dioxide and, accordingly, the transportation time of products decreases, with the intensity of rabbit carcass refrigeration decreased.

\section{References}

[1] Analysis of rabbit and hare meat market in Russia in 2011-2015: forecast for 2016-2020, Businesstat, Moscow: Research Store; 2016, p 93.

[2] M. Blinov, The program of import substitution in the Russian economy in 2014-2015, RIA Novosti, Moscow, 2015, retrieved from: https://ria.ru/spravka 20151125/1327022750.

[3] GOST 27747-2016, Rabbit meat (carcasses of rabbits, broilers and their parts). Technical conditions, 2018.01.01,Moscow: Standardinform, 2016 , p. 9.

[4] A. N. Grinyuk, E. N. Neverov, "Impact of carbon dioxide on the quality of refrigerated rabbit meat", Bulletin of the Krasnoyarsk State Agrarian University, 2018, No. 2, pp. 107-112.
[5] E. N. Neverov; A. N. Grinyuk; N.G. Tretyakov, "Use of carbon dioxide for cooling rabbit carcasses", Modern problems of science and education, 2015, no. 2; retrieved from: http://www.scienceeducation.ru/129-22318.

[6] E.N. Neverov, "Use of carbon dioxide for transportation of broiler chickens", Proceedings of the Kuban State Agrarian University, 2016, vol. 1 (58), pp. 236-239.

[7] V. A. Shlensky, I. I. Sudzilovsky, V. N. Martemyanov, A. N. Bogatyrev, A. I. Tsvetkov, N. D. Veretennikov, Device for cooling poultry and rabbit carcasses, Patent 2076288 the Russian Federation. IPC F25D17 / 02, claimed on 04/28/1994; published on 03/27/1997, p.5.

[8] V. N. Martemyanov, I. I. Sudzilovskiy, Yu. P. Aleshin, A. N. Bogatyrev Zh. I. Smirnova, V. E. Kutsakova, Device for cooling poultry and rabbit carcasses, Patent 2131099 the Russian Federation. IPC F25D17 / 02 , F25D13/06, claimed on 05/28/1998; published on 05/27/1999, p.7.

[9] V. E. Kutsakova, N. F. Krupenenkov, S. V. Frolov, I. I. Sudzilovskiy, The method of cooling poultry and rabbit carcasses after slaughter [Patent 2174304 the Russian Federation. IPC A23B4.06, F25D17 / 00, claimed on 06/10/2001; published on 10/10/2001, p.5.

[10] P. R. Bosher, R. Barnes, The method of transportation, storage or preparation for the transportation or storage of perishable goods Patent 2145406 Germany. IPC F25D1 1 / 02.B65D88 / 74, B65D19 / 38, claimed on 02/17/1995; published 10/02/2000, p. 11

[11] A. V. Tarashkevich, Container for storing and transporting fish in a preserving medium Patent 2235254 the Russian Federation. IPC F25D3 / 06, A23B4 / 06, claimed on 07/22/2002; published on 27/08/ 2004, p. 7.

[12] A. P. Rybkin, Automobile refrigerator, Patent 2235254 the Russian Federation. IPC B60H1 / 32, B60RZ / 20, F25B27 / 02 claimed on 10/01/2006; published on 01/10/2006, p. 3.

[13] T. A. Ruleva, N. Yu. Sarbatovm Breeding rabbits as a promising livestock industry, Young scientist. 2015, no.7, pp.306-308, retrieved from: https: //moluch.rirarchive/111/27809/

[14] E.V. Korotkaya, V.V. Kireev, Energy efficiency analysis of the sea buckthorn (hippophae rhamnoides) fruits quick freezing, Foods and Raw Materials, 2016. vol. 4, no. 1, pp. 110-120.

[15] E.V. Korotkaya, Effect of Freezing on the Biochemical and Enzymatic Activity of Lactobacillus Bulgaricus, Foods and Raw Materials, Vol.1, No. 2, 2013. pp. 9-16. 